\title{
Stab Injury of the Thoracic Spine with Remaining Metal Fragment - A Case Report -
}

\author{
Young-Gil Park, Kyoung-Tae Kim, Dae-Chul Cho, Joo-Kyung Sung \\ Department of Neurosurgery, Kyungpook National University School of Medicine, Daegu, Korea
}

Spinal stab injury is very rare. We report on a case of a 49-year-old female who was stabbed in the left posterior thoracolumbar area. Image study revealed that the remaining tip of the knife penetrated the spinal canal at the T11 level. After emergency T11 hemilaminectomy, the remaining tip of the knife was removed safely. She was discharged with no other complications; however, mild paresthesia persisted. If the metal fragment remains in the wound, surgery should be considered in order to prevent further delayed complications.

Key Words: Metal fragment $\cdot$ Spine $\cdot$ Stab injury

\section{INTRODUCTION}

Spinal stab injury is a very rare occurrence. In the United States, only $1 \%$ of spinal injury is due to stab injury ${ }^{3)}$. Most injuries result in an incomplete neurologic deficit due to spinal cord hemi-section ${ }^{11)}$. Even without acute neurologic symptoms, delayed symptoms or infection can occur ${ }^{6,8,18)}$. Due to its rarity, standard management strategies for this type of injury are still controversial ${ }^{4)}$. We report on a case of a 49 -year-old female who had mild sensory symptoms with a spinal stab injury that was treated surgically.

\section{CASE REPORT}

A 49-year-old female was stabbed several times on the back, hand, abdomen, and chest by a robber. On arrival, her vital signs were as follows: blood pressure, $87 / 70 \mathrm{mmHg}$; pulse, 88; Oxygen saturation using a pulse oxymeter, $99 \%$.

Her physical examination revealed 6 stab wounds; 4 were on the chest and abdomen, 1 was on the left wrist, and 1 was on the left side of back. On neurological examination, she had mild paresthesia on the left side of trunk and no motor

- Received: Mar 15, 2011 - Accepted: May 24, 2011

- Published: Jun 21, 2011

Corresponding Author: Dae-Chul Cho, MD

Department of Neurosurgery, Kyungpook National University Hospital 50

Samduk-2-ga, Jung-gu, Daegu, 700-721, Republic of Korea

Tel: +82-53-420-6524, Fax: +82-53-423-0504

E-mail: jodc06484@yahoo.co.kr weakness. Her total blood count and biochemical tests were within normal limits. A metallic object was observed in a thoracolumbar spine X-ray (Fig. 1). Chest and abdomen computed tomography (CT) revealed a left hemo-pneumothorax and perforated stomach. Axial CT and lateral reconstruction CT showed that the tip of the knife traversed the lateral portion of the spinal canal and stuck into the pedicle and posterior body of the T11 spine (Fig. 2). The patient underwent on an urgent surgery in the prone position. Following a midline

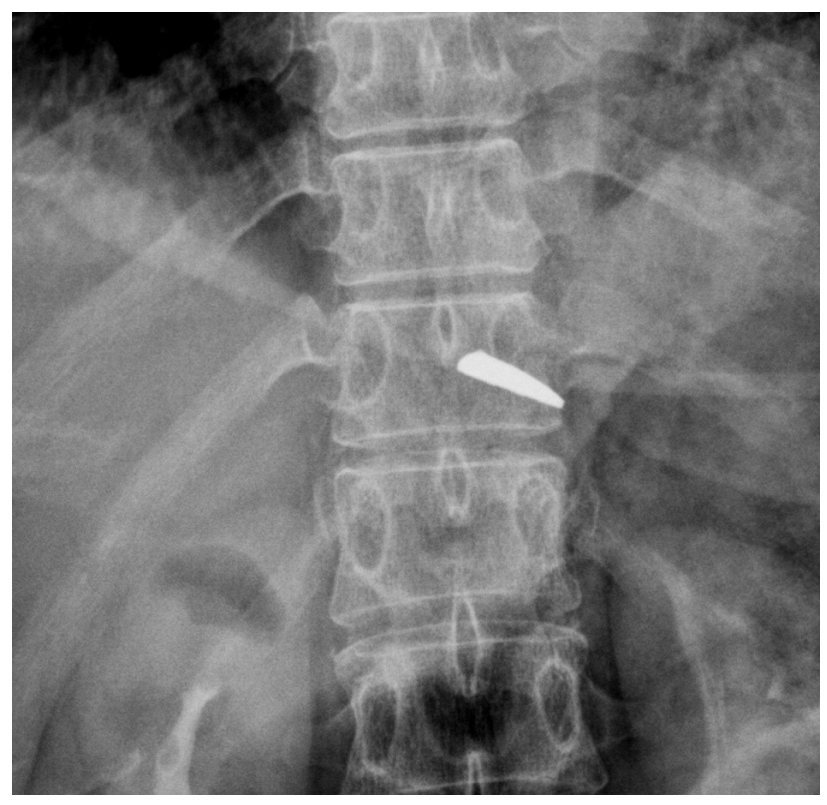

Fig. 1. Anteroposterior $\mathrm{X}$-ray shows a metallic object at the $\mathrm{T} 11$ level. 

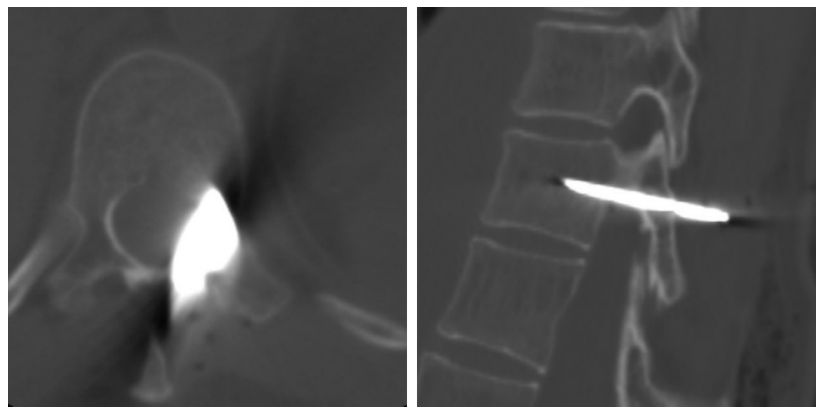

Fig. 2. Computerized tomography revealed a metallic object that traversed the lateral portion of the spinal canal and stuck into the pedicle and posterior body of the T11 vertebra.

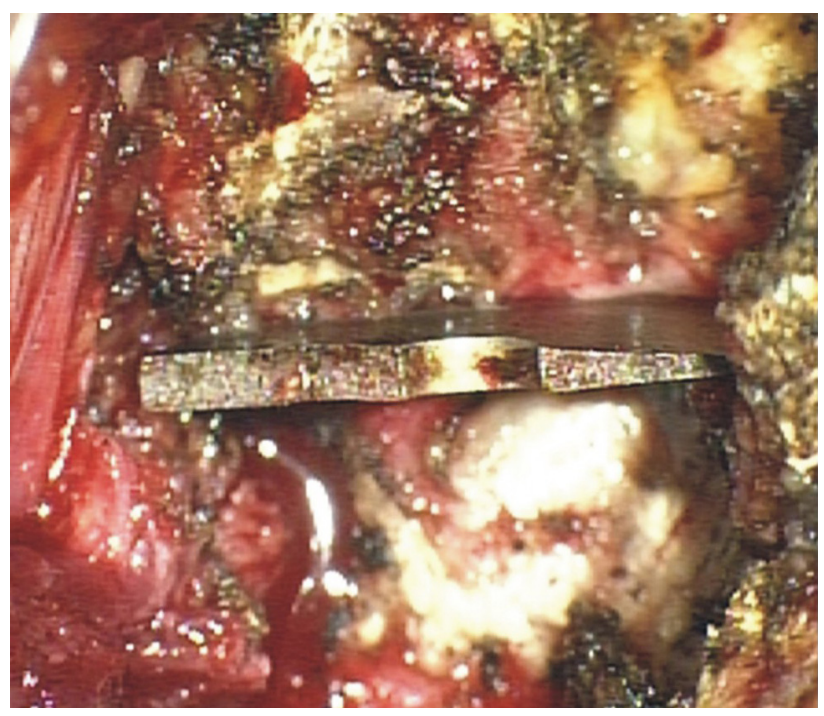

Fig. 3. A broken tip of a knife was detected at the posterior portion of the left lamina of $\mathrm{T} 11$.

T10-T12 skin incision, a broken tip of a knife was detected at the posterior portion of the left lamina of T11 (Fig. 3). After a left T11 hemilaminectomy, the broken tip was removed (Fig. 4). A copious cerebrospinal fluid (CSF) leakage from dura tear was observed at the shoulder of the exiting root and ventrolateral portion of the thecal sac. Fortunately, there was no direct damage to the spinal cord. After primary repair of dura with 7-0 prolene, a lumbar drainage was installed to prevent CSF leakage. After the surgery, video assisted thoracotomy, open exploration, and closure of the perforated stomach were performed. Five days after the surgery, the wound was found to be clean without CSF leakage. We increased level of lumbar drainage up to $20 \mathrm{~cm}$ from heart. After confirming of no CSF leakage, we removed the lumbar drainage. We administered intravenous ceftriaxone and metronidazole for 2 weeks, and tetanus prophylaxis was administered. The patient had no further complications and was discharged regularly;

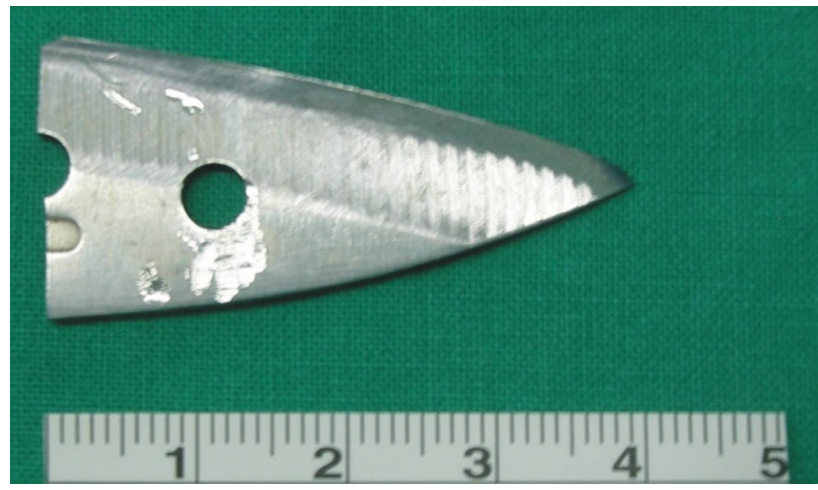

Fig. 4. The tip of the knife.

however, mild paresthesia persisted on left T11 sensory dermatome. It may be due to damage of left T11 nerve root.

\section{DISCUSSION}

Spinal stab injuries are very rare and most are caused by assault from the rear ${ }^{5,16}$. The vast majority of such injuries present with acute neurologic symptoms. Acute neurologic symptoms can be due to direct penetration of spinal cord neural elements, spinal cord infarction, and epidural hematoma. When direct penetrating injury occurs, the patient may present with typical Brown-Sequard variants ${ }^{6,12}$. Artery of Adamkiewicz injury can cause spinal cord infarction, which can be exacerbated by systemic hypotension ${ }^{12}$. Epidural hematoma was a very rare complication of spinal stab injury ${ }^{9}$. Some patients present with delayed neurologic symptoms. Remaining fragments in the spinal canal may cause slow, progressive damage ${ }^{6,8)}$.

When the diagnosis of remote spinal stab injury is considered, the initial work-up consists of plain radiographs for identification of any remaining knife fragments. As further imaging study, CT scan may be helpful ${ }^{13)}$. However, in some cases, significant metallic artifact was created by the remaining knife fragment. Magnetic resonance imaging (MRI) has great benefit in ruling out space-occupying lesions. However, performance of MRI in the presence of a remaining fragment could be dangerous, because movement of the fragment in a strong magnetic field could result in worsening of neurologic sym- ptoms ${ }^{8)}$.

Management of a spinal stab injury must be individualized, and must be undertaken with utmost care in order to avoid undue injury during surgery. In particular, movement of the fragment must be minimized, and electrocautary must not be used $^{8}$. Moreover dura around the spinal cord must be closed watertightly in order to avoid CSF leakage. Accepted management of patients with incomplete neurological deficits after spinal stab injury involves removal of metallic foreign material, due to the risk of late complications, such as myelopahty, pro 
gressive neurological deficit, intramedullary abscess, and symptomatic pseudomeningocele ${ }^{6,8,10,18)}$. These delayed complications are the result of inflammation and scar tissue that have been shown to develop around retained fragments with arachnoid adhesions and extensive spinal cord gliosis ${ }^{6}$. After spinal stab injury, infection was a rare but serious complication. To prevent infection, intravenous broad spectrum antibiotics and tetanus prophylaxis are required. In our case, we did tetanus prophylaxis and used intravenous ceftriaxone and metronidazole for 2 weeks. Despite neurological symptoms, use of steroids is not recommended due to a lack of definite evidence and its detrimental effects on wound healing ${ }^{17)}$.

Additionally, lumbar drainage could be installed to prevent CSF leakage. There are several indications for lumbar drainage including improvement of surgical exposure in neurosurgical procedures, protection of the spinal cord during repair of thoracic aorta, shot-term treatment of hydrocephalus and treatment of CSF fistula ${ }^{1)}$. In our case, lumbar drainage was installed for the prevention of CSF fistula. If no CSF leakage was confirmed by absence of additional subcutaneous accumulation of fluid at the operative site, postural headaches, clinical signs of pseudomeningocele formation and cutanenous leakage of CSF at increased level of lumbar drainage ${ }^{7}$, it should be removed as soon as possible for the prevention of catheter related infection ${ }^{2,14,15)}$. Also we confirmed no CSF leakage at elevated height of lumbar drainage and removed lumbar drainage catheter carefully.

Prognosis for spinal stab injury is generally better than that for blunt spinal cord injury. Most patients present with incomplete spinal cord injuries, and up to $66 \%$ show good recovery ${ }^{17}$. She also had no further complications except mild paresthesia persisted. Three months after the surgery, she had mild improvement of pareshesia without other complications.

\section{CONCLUSION}

We report a very rare case of spinal stab injury with remaining fragment. Management of spinal stab injury is controversial. However, to avoid delayed complication, surgical removal and use of prophylactic antibiotics should be considered.

\section{REFERENCES}

1. Basauri LT, Concha-Julio E, Selman JM, Cubillos P, Rufs J: Cerebrospinal fluid spinal lumbar drainage: indications, technical tips, and pitfalls. Crit Rev Neurosurg 9:21-27, 1999

2. Bota DP, Lefranc F, Vilallobos HR, Brimioulle S, Vincent JL:
Ventriculostomy-related infections in critically ill patients: a 6-year experience. J Neurosurg 103:468-472, 2005

3. Burney RE, Maio RF, Maynard F, Karunas R: Incidence, characteristics, and outcome of spinal cord injury at trauma centers in North America. Arch Surg 128:596-609, 1993

4. CM Park, DY Kim, JH Jeong, YS Park: Transection of the spinal cord following anterior cervical stab injury: a caser report. Kor J spine 7:261-264, 2010

5. Doğan S, Kocaeli H, Taşkapilioğlu MO, Bekar A: Stab injury of the thoracic spinal cord: case report. Turk Neurosurg 18: 298-301, 2008

6. Jones FD, Woosley RE: Delayed myelopathy secondary to retained intraspinal metallic fragment. Case report. J Neurosurg 55:979-982, 1981

7. Kitchel SH, Eismont FJ, Green BA: Closed subarachnoid drainage for management of cerebrospinal fluid leakage after an operation on the spine. J Bone Joint Surg Am 71:984-987, 1989

8. Kulkarni AV, Bhandari M, Stiver S, Reddy K: Delayed presentation of spinal stab wound: case report and review of the literature. J Emerg Med 18:209-214, 2000

9. Olshaker JS, Barish RA: Acute traumatic cervical epidural hematoma from a stab wound. Ann Emerg Med 20:662-664, 1991

10. Pal HK, Bhatty GB, Deb S, Mishra S: Traumatic pseudomeningocele at cranio-vertebral junction following stab injury. Injury 29:142-143, 1998

11. Peacock WJ, Shrosbree RD, Key AG: A review of 450 stab wounds of the spinal cord. S Afr Med J 51:961-964, 1977

12. Rogers FB, Osler TM, Shackford SR, Wald SL: Isolated stab wound to the artery of Adamkiewicz: case report and review of the literature. J Trauma 43:549-551, 1997

13. Rubin G, Tallman D, Sagan L, Melgar M: An unusual stab wound of the cervical spinal cord: a case report. Spine 26: 444-447, 2001

14. Schade RP, Schinkel J, Visser LG, Van Dijk JM, Voormolen $\mathrm{JH}$, Kuijper EJ: Bacterial meningitis caused by the use of ventricular or lumbar cerebrospinal fluid catheters. J Neurosurg 102:229-234, 2005

15. Scheithauer S, Bürgel U, Bickenbach J, Häfner H, Haase G, Waitschies B, Reinges MH, Lemmen SW: External ventricular and lumbar drainage-associated meningoventriculitis: prospective analysis of time-dependent infection rates and risk factor analysis. Infection 38:205-209, 2010

16. Simpson RK Jr, Venger BH, Narayan RK: Treatment of acute penetrating injuries of the spine: A retrospective analysis. $\mathrm{J}$ Trauma 29:42-46, 1989

17. Velmahos GC, Degiannis E, Hart K, Souter I, Saadia R: Changing profiles in spinal cord injuries and risk factors influencing recovery after penetrating injuries. J Trauma 38:334-337, 1995

18. Wright RL.: Intramedullary spinal cord abscess. Report of a case secondary to stab wound with good recovery following operation. J Neurosurg 23:208-210, 1965 